\title{
The effect of mutation status, pathological features and tumor location on prognosis in patients with colorectal cancer
}

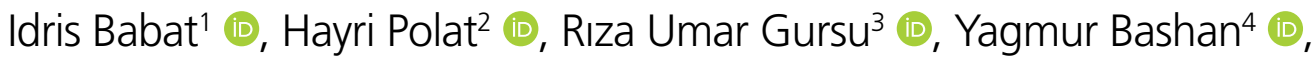 \\ Ali Kırık ${ }^{5}$ (1), Hasan Bektas ${ }^{6}$ (1), Serkan Sarı ${ }^{6}$, Çiğgdem Usul Afşar ${ }^{5 *}$ (1)
}

\begin{abstract}
SUMMARY
OBJECTIVE: Colorectal cancer is the most common malignancy of the gastrointestinal tract. It is the third most common tumor in both genders and the second reason of cancer-related deaths. In recent years, tumor location has gained importance as a prognostic indicator. In this study, we aimed to analyze if there was a prognostic effect of tumor location, the pathological features, and the mutation status of patients on survival.

METHODS: Two-hundred and ten colorectal cancer patients aged 18 years and older were included into the study. One-hundred and forty-two patients had left-sided tumor and 68 patients had right-sided tumor. Patients who had other malignancies rather than squamous cell skin cancer and in situ cervical cancer were excluded. All statistical tests were carried out using two-sided process, and a p $\leq 0.05$ was considered statistically significant.

RESULTS: There were 140 men and 70 women in the study. The median age of the patients was 62 years old. There was no statistically significant difference according to tumor location and survival of patients. The overall survival of patients with right-sided tumors was 60.5 months and 47.2 months for left-sided tumors. Disease-free survival of patients was 63.7 months for right-sided tumors and 46 months for left-sided ones. Perineural invasion, grade and stage were crucial prognostic parameters. Disease-free survival was longer for female colorectal cancer patients.

CONCLUSION: According to our study, survival of patients was similar regardless of tumor location. This can be explained by the different sequencing of treatment strategies and divergent population genetics.

KEYWORDS: Colorectal neoplasms. Prognosis. Mutation.
\end{abstract}

\section{INTRODUCTION}

Colorectal cancer originating from either the colon or rectum is the third most common cancer diagnosed worldwide ${ }^{1}$. According to the World Health Organization Global Cancer Observatory (GLOBOCAN) database, colorectal cancer is the third most common cancer diagnosed in males and the second in females, with an estimated 1.8 million new cases and 861,000 deaths occurring in 2018 worldwide 2 .

Colorectal cancer encompasses a heterogeneous group of diseases with complex genetic and epigenetic risk factors, such

\footnotetext{
${ }^{1}$ Marmara Ereğlisi District Hospital, Department of Internal Medicine - İstanbul, Turkey.

${ }^{2}$ Istanbul Education and Research Hospital, Department of Internal Medicine - Istanbul, Turkey.

${ }^{3}$ Acibadem Bakirköy Hospital, Department of Medical Oncology - Bakırköy/lstanbul, Turkey.

${ }^{4}$ Sultangazi Haseki Education and Research Hospital, Department of Internal Medicine and Nephrology - Sultangazi/lstanbul, Turkey.

${ }^{5}$ Balıkesir University Medical Faculty, Department of Internal Medicine and Medical Oncology - Balıkesir, Turkey.

${ }^{6}$ Health Sciences University, Istanbul Education and Research Hospital, Department of Surgery - Istanbul, Turkey.

*Corresponding author: cigdemusul@yahoo.com

Conflicts of interest: the authors declare there is no conflict of interest. Funding: none.

Received on August 23, 2020. Accepted on October 31, 2020.
} 
as tumor location, microsatellite instability, western lifestyle, physical inactivity, obesity, smoking and vitamin $\mathrm{D}$ deficiencies $^{3,4}$. Studies in the literature have shown that prognostic status and survival rates differ between right- and left-sided colorectal tumors. However, the effect of location differences on survival does not show consistent variability in different tumor stages ${ }^{5,6}$. On the other hand, most studies revealed a poorer survival in right-sided primary tumor location ${ }^{7-9}$.

Alongside tumor location, different pathological signs that affect colorectal cancer prognosis have also been identified. These pathological signs include variable factors, such as lymphovascular invasion, perineural invasion, tumor border configuration and host immune response to tumor ${ }^{10,11}$. In particular, "blood or lymphatic vessel invasion" in patients with colorectal cancer was reported by the College of American Pathologists (CAP) Consensus Statement as a prognostic status ${ }^{12}$.

Colorectal cancer is a clinical entity that is rich in mutation diversity, in which genetic alterations are well defined in Oncology. At the same time, different genetic factors, such as K-RAS, N-RAS, BRAF and HER2, are known to affect the prognosis of colorectal cancer. Furthermore, microsatellite stabilization status is also as important as other prognostic factors ${ }^{13,14}$. Both these mutations and other prognostic signs observed in colorectal cancer progression affect the course of the disease, and this clinical process makes individualized treatment important for each patient.

In this study, we aimed to investigate the effect of tumor sidedness, pathological features and mutation status on survival in colorectal cancer patients.

\section{METHODS}

In this retrospective study, medical records of patients with histopathologically proven colorectal cancer between the dates of January 1, 2010 and December 31, 2016 were evaluated. Ethical approval was taken from our institution before the onset of study. There were 210 patients aged 18 years and older of whom 142 had left-sided tumors and 68 had right-sided tumors.

The exclusion criteria were as follows: any malignancy other than treated squamous cell skin cancer and in situ cervix carcinoma, not histopathologically proven colorectal cancer; any death other than colorectal cancer; and patients who lost their six-month follow-up at outpatient clinic. Age, gender, tumor location, histological tumor grade, disease stage, lymphovascular invasion, perineural invasion, comorbidities, such as type 2 diabetes, K-RAS, N-RAS and BRAF mutation status, overall survival, disease-free survival and progression-free survival of patients, were recorded. Right-sided tumors were defined as caecum and ascending colon; left-sided tumors were defined as descending colon, sigmoid colon, rectosigmoid region and the rectal region. Grade 1 and 2 tumors were defined as low grade, grade 3 tumors were defined as high grade. Grades 1 (well differentiated) and 2 (medium differentiated) were defined as low; grade 3 (poorly differentiated) was defined as high-grade tumor.

The staging of metastatic patients was done by using various imaging modalities, such as computed tomography, magnetic resonance imaging, and positron emission tomography/ computed tomography scan. Patients were staged according to the International Union Against Cancer TNM classification.

Continuous variables were categorized using median values as the cutoff point. For group comparison of categorical variables, chi-square or one-way ANOVA tests were used; and for comparison of continuous variables, Mann-Whitney $U$ test or Kruskall-Wallis tests were accomplished. Overall survival was calculated from the date of first admission to the clinics to disease-related death or date of last contact with the patient or any family member. Kaplan-Meier method was used for the estimation of survival distribution, and differences in overall survival was assessed by the log-rank statistics. All statistical tests were carried out using two-sided tests and a $\mathrm{p} \leq 0.05$ was considered statistically significant. Statistical analysis used the SPPS 21.0 (SPSS Inc., Chicago, IL., USA) software.

\section{RESULTS}

There were 210 patients with histopathologically confirmed colorectal cancer of whom $142(67.6 \%)$ had left-sided tumors and $68(32.4 \%)$ had right-sided tumors. Seventy (33.3\%) patients were female and $140(66.7 \%)$ were male. The median age of the patients was 62 (range: 20-83) years. General characteristics of the patients were summarized in Table 1 .

K-RAS mutation was positive in $33(15.7 \%)$ patients, negative in $37(17.6 \%)$ and unknown in 140 (66.7\%). Thirty-four (16.2\%) patients had type 2 diabetes mellitus as comorbidity. During their follow-up, 75 (35.7\%) patients had progression. Eighty-six (41\%) patients were not alive at the end of study.

There was no statistically significant difference according to the overall survival of patients with right- and left-sided tumors (60.5 months and 47.2 months, respectively, $\mathrm{p}>0.05$ ), as seen in Figure 1. Patients with higher grade lived shorter than the ones with lower grade (overall survival=21 and 59.8 months respectively, $\mathrm{p}<0.0001$ ), as in Figure 2. Stage was an independent surrogate of survival and patients with stage III-IV lived shorter (39.4-76 months, respectively, $\mathrm{p}<0.0001$ ). RAS status had no effect on survival $(\mathrm{p}=0.78)$. Diabetes as comorbidity had no effect on survival $(\mathrm{p}=0.13$ for overall survival and $\mathrm{p}=0.09$ for progression-free survival/disease-free survival). There was no statistically significant difference in terms of overall survival 
between males ( 47.4 months) and females ( 57.4 months), with $\mathrm{p}>0.05$, but disease-free survival was higher in females (60.6 versus 48.8 months, $\mathrm{p}=0.02$ ). Perineural invasion was considered to be important for disease-free survival (37.7 versus 63.8 months, respectively, $\mathrm{p}<0.0001$ ).

\section{DISCUSSION}

Colorectal cancer survival rates are increasing due to sequential and good therapeutic management of patients. Disease stage, age, histological grade/tumor differentiation, lymphovascular invasion and perineural invasion are crucial prognostic parameters $^{15,16}$.

The prognostic impact of tumor sidedness is a crucial factor for colorectal cancer. Right-sided colorectal cancers are known to have higher mortality with shorter survival than the left-sided ones ${ }^{17-20}$. In our study, there was no statistically significant difference of overall survival and disease-free survival/ progression-free survival according to tumor sidedness. In a study done by Liu et al. ${ }^{19}$, in Chinese population, it was shown that right-sided tumors had a worse prognosis. In another prospective study done by Jess et al. ${ }^{17}$, for Danish colorectal cancer patients, right-sided tumors had a higher mortality rate in the first two years of their follow-up. Hansen et al. ${ }^{20}$ showed that right-sided tumors had worse prognosis than the left-sided ones.

For K-RAS wild type colorectal cancer, in which all patients had an anti-epidermal growth factor receptor antibody with chemotherapy, right-sided tumors had worse overall survival, progression-free survival and objective response rate ${ }^{17}$. Wolmark et al. ${ }^{21}$ concluded that descending colon cancer patients had better prognosis than rectal and other localized ones. However, Sjo et al..$^{22}$ showed that descending colon and transverse colon cancers had worse prognosis. In a new study, rectal cancer was associated with worse Refeeding syndrome compared to right-sided colon cancer and left-sided colon cancer, however among patients with recurrence, rectal cancer was associated with better overall survival compared to right-sided colon cancer and worse overall survival compared to left-sided colon cancer ${ }^{23}$. A study performed

Table 1. General characteristics of the patients.

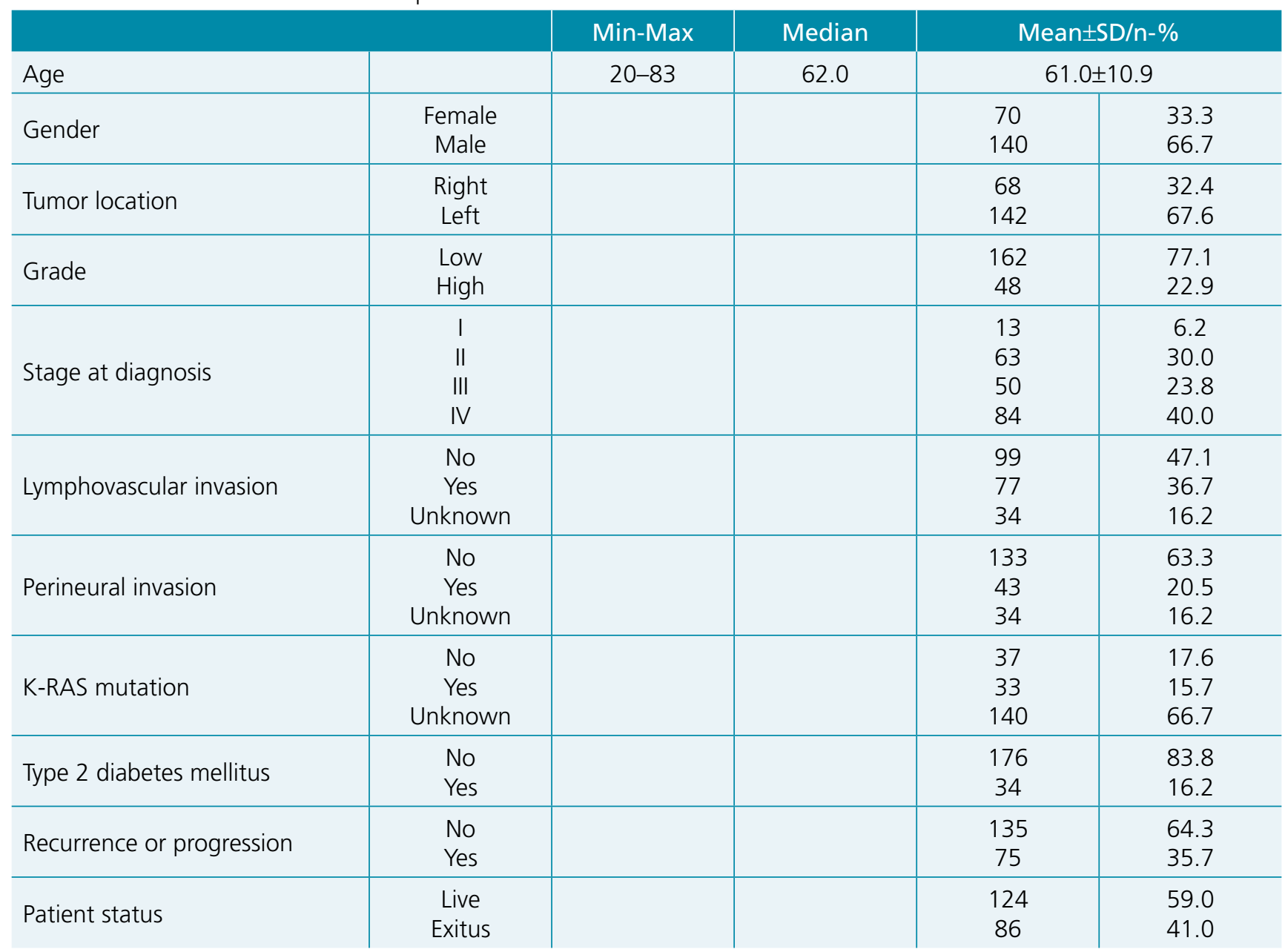

SD: standard deviation. 
in the Turkish population has showed that tumor side has no effect on survival. ${ }^{24}$. It was similar to our findings. In 2020, new data demonstrated that there was no consensus with respect to the implications of tumor sidedness in second and subsequent lines of treatment, and the concept of tumor sidedness may not be true in this setting. There is certainly a need for a consensus statement in this space ${ }^{25}$.

In literature, there is no gender diversity ${ }^{24}$, but in our study, male/female ratio was $2 / 1$. Türkoğlu et al. ${ }^{24}$ found no prognostic impact of gender on survival. In our study, overall survival was the same for both males and females, but progression-free and disease-free survival were shorter in males than females.

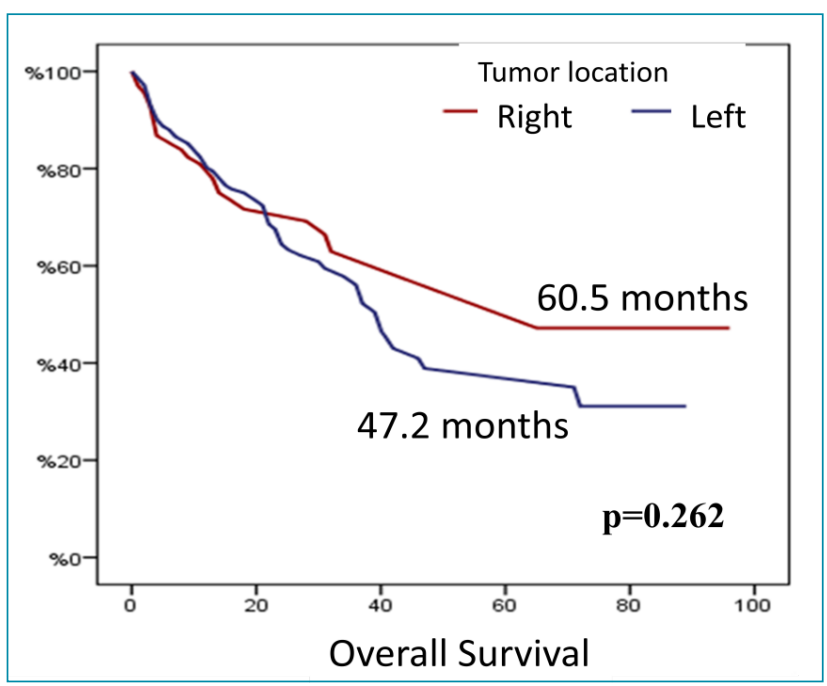

Figure 1. The effect of tumor location on overall survival.

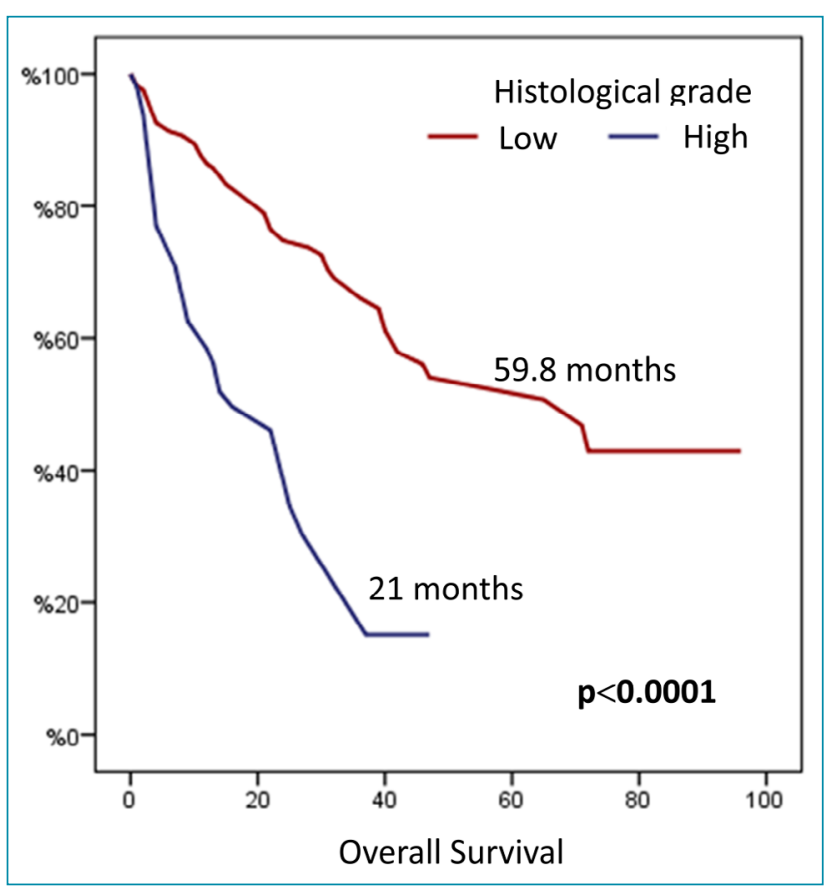

Figure 2. The effect of histological grade on overall survival.
In literature, lymphovascular invasion is considered to be a poor prognostic factor ${ }^{16}$. However, it was not a good surrogate of prognosis in our study. Perineural invasion is associated with tumor recurrence and it is a poor prognostic factor for colorectal cancer patients ${ }^{15,16}$. In our study, there was no difference on overall survival according to perineural invasion, thus progression-free and disease-free survival were shorter in patients with perineural invasion.

We found no prognostic effect of K-RAS status, but our sample size was too small to show the difference. N-RAS and BRAF mutations were also available in a limited number of patients. This is one of the study limitations. We should state that in our country RAS mutation test was not available in all hospitals and, for many years, patients with stage IV tumors had computed tomography with anti-vascular endothelial growth factor receptor antibodies at first line regardless of their tumor side. Nowadays, it is available and we start therapies with anti-epidermal growth factor receptor antibodies in patients with left-sided tumors and RAS wild type tumors. On the other hand, we still perform computed tomography with anti-vascular endothelial growth factor receptor to right-sided tumors regardless of their RAS status at first line. So all patients had computed tomography with anti-visual evoked flow response at first line regardless of their tumor side and RAS status. This might be a factor by which we found no statistically significant difference of survival due to tumor sidedness.

\section{CONCLUSION}

We have shown that perineural invasion, stage and grade were prognostic indicators for colorectal cancer patients. However, gender, age, RAS status and tumor side had no effect on survival in Turkish population. Larger and prospective studies are needed.

\section{AUTHORS" CONTRIBUTIONS}

IB: Conceptualization, Writing - Original Draft, Writing Review \& Editing. HP: Conceptualization, Writing - Original Draft, Writing - Review \& Editing. RUG: Conceptualization, Writing - Original Draft, Writing - Review \& Editing. YB: Conceptualization, Writing - Original Draft, Writing Review \& Editing. AK: Conceptualization, Writing - Original Draft, Writing - Review \& Editing. HB: Conceptualization, Writing - Original Draft, Writing - Review \& Editing. SS: Conceptualization, Writing - Original Draft, Writing - Review \& Editing. AC: Conceptualization, Writing - Original Draft, Writing - Review \& Editing. 


\section{REFERENCES}

1. Siegel R, Naishadham D, Jemal A. Cancer statistics, 2013. CA Cancer J Clin. 2013;63(1):11-30. https://doi.org/10.3322/ caac. 21166

2. International agency for research on cancer [Internet]. Cancer today: cancer fact sheets. [cited on July 4, 2019]. Available from: http://gco.iarc.fr/today/fact-sheets-cancers

3. Testa U, Pelosi E, Castelli G. Colorectal cancer: genetic abnormalities, tumor progression, tumor heterogeneity, clonal evolution and tumor-initiating cells. Med Sci (Basel). 2018;6(2):31. https://doi.org/10.3390/medsci6020031

4. Mattiuzzi C, Sanchis-Gomar F, Lippi G. Concise update on colorectal cancer epidemiology. Ann Transl Med. 2019;7(21):609. https://doi.org/10.21037/atm.2019.07.91

5. Karim S, Brennan K, Nanji S, Berry SR, Booth CM. Association between prognosis and tumor laterality in early-stage colon cancer. JAMA Oncol. 2017;3(10):1386-92. https://doi.org/ 10.1001/jamaoncol.2017.1016

6. Huang CW, Tsai HL, Huang MY, Huang CM, Yeh YS, Ma CJ, et al. Different clinicopathologic features and favorable outcomes of patients with stage III left-sided colon cancer. World J Surg Oncol. 2015;13:257. https://doi.org/10.1186/ s12957-015-0640-4

7. Benedix F, Kube R, Meyer F, Schmidt U, Gastinger I, Lippert H, et al. Comparison of 17,641 patients with right- and left-sided colon cancer: differences in epidemiology, perioperative course, histology, and survival. Dis Colon Rectum. 2010;53(1):57-64. https://doi.org/10.1007/DCR.0b013e3181c703a4

8. Derwinger K, Gustavsson B. Variations in demography and prognosis by colon cancer location. Anticancer Res. 2011;31(6):2347-50. PMID: 21737663

9. Jess P, Hansen IO, Gamborg M, Jess T, Danish Colorectal Cancer Group. A nationwide Danish cohort study challenging the categorisation into right-sided and left-sided colon cancer. BMJ Open. 2013;3(5):e002608. https://doi.org/10.1136/ bmjopen-2013-002608

10. Compton CC. Colorectal carcinoma: diagnostic, prognostic, and molecular features. Mod Pathol. 2003;16(4):376-88. https://doi.org/10.1097/01.MP.0000062859.46942.93

11. Harris El, Lewin DN, Wang HL, Lauwers GY, Srivastava A, Shyr $Y$, et al. Lymphovascular invasion in colorectal cancer: an interobserver variability study. Am J Surg Pathol. 2008;32(12):1816-21. https://doi.org/10.1097/ PAS.0b013e3181816083

12. Compton CC, Fielding LP, Burgart LJ, Conley B, Cooper HS, Hamilton SR, et al. Prognostic factors in colorectal cancer. College of American Pathologists Consensus Statement 1999. Arch Pathol Lab Med. 2000;124(7):979-94. https://doi. org/10.1043/0003-9985(2000)124<0979:PFICC>2.0.CO;2

13. Afrăsânie VA, Marinca MV, Alexa-Stratulat $T$, Gafton $B$, Păduraru M, Adavidoaiei AM, et al. KRAS, NRAS, BRAF, HER2 and microsatellite instability in metastatic colorectal cancer - practical implications for the clinician. Radiol Oncol. 2019;53(3):265-74. https://doi.org/10.2478/raon-2019-0033
14. Therkildsen $C$, Bergmann TK, Henrichsen-Schnack T, Ladelund $S$, Nilbert $M$. The predictive value of KRAS, NRAS, BRAF, PIK3CA and PTEN for anti-EGFR treatment in metastatic colorectal cancer: A systematic review and meta-analysis. Acta Oncol. 2014;53(7):852-64. https://doi.org/10.3109/02 84186X.2014.895036

15. Compton CC. Colorectal carcinoma: diagnostic, prognostic, and molecular features. Mod Pathol. 2003;16(4):376-88. https://doi.org/10.1097/01.MP.0000062859.46942.93

16. Wolpin BM, Meyerhardt JA, Mamon HJ, Mayer RJ. Adjuvant treatment of colorectal cancer. CA Cancer J Clin. 2007;57(3):16885. https://doi.org/10.3322/canjclin.57.3.168

17. Jess P, Hansen IO, Gamborg M, Jess T, Danish Colorectal Cancer Group. A nationwide Danish cohort study challenging the categorisation into right-sided and left-sided colon cancer. BMJ Open. 2013;3(5):e002608. https://doi.org/10.1136/ bmjopen-2013-002608

18. Arnold D, Lueza B, Douillard JY, Peeters $M$, Lenz HJ, Venook A, et al. Prognostic and predictive value of primary tumour side in patients with RAS wild-type metastatic colorectal cancer treated with chemotherapy and EGFR directed antibodies in six randomized trials. Ann Oncol. 2017;28(8):1713-29. https:// doi.org/10.1093/annonc/mdx175

19. Liu F, Li C, Jia H, Yang L, Wu Y, Zhao J, et al. Is there a prognostic value of tumor location among Chinese patients with colorectal cancer? Oncotarget. 2017;8(24):38682-92. https://doi.org/10.18632/oncotarget.16305

20. Hansen IO, Jess P. Possible better long-term survival in left versus right-sided colon cancer - a systematic review. Dan Med J. 2012;59(6):A4444. PMID: 22677242

21. Wolmark N, Wieand HS, Rockette HE, Fisher B, Glass A, Lawrence $W$, et al. The prognostic significance of tumor location and bowel obstruction in Dukes $B$ and $C$ colorectal cancer. Findings from the NSABP clinical trials. Ann Surg. 1983;198(6):743-52. https://doi.org/10.1097/00000658-198312000-00013

22. Sjo OH, Lunde OC, Nygaard K, Sandvik L, Nesbakken A. Tumour location is a prognostic factor for survival in colonic cancer patients. Colorectal Dis. 2008;10(1):33-40. https:// doi.org/10.1111/j.1463-1318.2007.01302.x

23. Shida D, Inoue M, Tanabe T, Moritani K, Tsukamoto S, Yamauch $S$, et al. Prognostic impact of primary tumor location in stage III colorectal cancer-right-sided colon versus left-sided colon versus rectum: a nationwide multicenter retrospective study. J Gastroenterol. 2020;55(10):958-68. https://doi.org/10.1007/ s00535-020-01706-7

24. Türkoğlu A, Çetinkaya Z, Girgin M, Ayten R, Kanat BH, Binnetoğlu K, et al. Kolorektal kanserlerde prognostik faktörler. Dicle Tıp Dergisi. 2014;41(4):724-31. https://doi.org/10.5798/ diclemedj.0921.2014.04.0507

25. Bahl A, Talwar V, Sirohi B, Mehta P, Arya D, Shrivastava G, et al. Primary tumor location as a prognostic and predictive marker in metastatic colorectal cancer (mCRC). Front Oncol. 2020;10:964. https://doi.org/10.3389/fonc.2020.00964 